\title{
Editorial: The Workplace Innovation Debate Expands
}

Richard Ennals 
Issue 1.1 of the European Journal for Workplace Innovation (EJWI) comprised introductory overview articles by leading researchers. The journal was founded to take forward debates that have been initiated by, among others, the European Workplace Innovation Network (EUWIN). The editorial made it clear that EJWI seeks to be pluralist, rather than imposing a particular view or model. It offers an arena where a number of previously separate discourses can meet.

EJWI is hosted by the University of Agder, Norway. In principle there is scope for development of the new journal, with potential benefits for research, practice and education. Success depends on people registering on the website, and then contributing articles, extending the debate.

The articles in Issue 2.1 make reference to a number of the articles from Issue 1.1, taking them as foundations. As the editors had hoped, they broaden the scope of discussion. This trend continues in Issue 2.2, which is now in preparation, with submissions now under review. In both cases, reference is made to numerous cases across Europe. EU policies and programmes have provided a basis for international benchmarking.

We can conclude that Workplace Innovation is the name of a lively arena for dialogue, where it is important to listen to different points of view, rather than expecting overall agreement. The articles develop a number of debates, in which Workplace Innovation plays an important role, even without formal definition. Indeed, reference to practice as well as to theory saves us from unnecessary pedantry. Workplace Innovation begins to take shape when it is explored against the background of differences. The first article considers Industry 4.0 in Germany, and explores the need for humanisation influenced by Workplace Innovation. We are back in the old debate about techno-centric and anthropocentric systems, technology and human skill, which has been running since the 1980s. As in the past, the focus on technology has been initially popular. Hopes tend not to be matched by experience. Can a complementary focus on Workplace Innovation produce repeatable results?

The second article considers the potential contribution of Workplace Innovation to the work and health of older workers. With a formidable assembly of references on occupational psychology and workplace health, they argue that, rather than customising arrangements for specific groups such as older workers, developing the workplace in line with innovative working practices is likely to bring benefits for older workers. The article is an outcome of the EU WORKAGE project, which involved major interventions in two public sector organisations. We await the findings regarding the impact of innovative working practices on, for example, retirement plans.

The third article, on innovation practices in Swedish municipalities, brings several helpful reminders. Much of the recent literature on innovation has concentrated on the private sector, and in particular on manufacturing. This has left many public sector organisations confused and uncertain. Lessons may be learned from WORKAGE, and the arguments in the previous article. The article highlights the lack of innovation in the public sector, and begins to make reference to the possible implications of Workplace Innovation and innovative working practices.

The fourth article considers High Performance Work Practices, and their diffusion in Europe. There are familiar arguments about leading edge cases, and the long tail of organisations which are slower to change. There is a compendious literature review, and a valuable summary account of different national programmes which are intended to aid and sustain processes of diffusion. 
My own article on Wittgenstein and his followers is the last to be included in Issue 2.1. The relevance of the argument may be seen from the inclusion of Göranzon and Gustavsen among the followers. The later Wittgenstein was no respecter of grand theory: he recommended the use of practical cases. He emphasised the importance of family resemblances, language games and forms of life. We might imagine the emergence of a new dialogue on working life, in which participants could see beyond their own traditions, and find some resemblances between their cases and those of others.

Workplace Innovation takes a human centred approach to technology and innovation. We find this in many research traditions, including socio-technical systems and even project management, where researchers take an approach which emphasises people rather than systems. As EJWI develops, it is likely to include articles from more different traditions. Issue 2.2 is likely to include Health and Safety, Territorial Development, Education, Participation, Gender and Power. In each case, there is a fresh perspective on Workplace Innovation.

Workplace Innovation invites ongoing dialogue. We are not all obliged to agree. In fact, if we were all to agree, the dialogue would not be sustained. On this basis, it is probably important that we do not rush into tight definitions of Workplace Innovation. EJWI offers a new arena in which many views can be explored. We have the opportunity to draw on both theory and practice. We need accounts of case study experience. These may come from practitioners, without elaborate theoretical underpinning.

EJWI is free, open access and online. It can provide a platform for a fresh collaborative approach to education, in contrast to MOOCs, which tend to be driven by large universities. Taking the twin backgrounds of work and learning, there is an important opportunity to engage in international dialogue, collaborating across borders of countries and disciplines. We can publish articles which are practical in orientation, rather than conventionally academic. We can broker new collaborations and partnerships, creating collaborative advantage.

Workplace Innovation places the focus on people, rather than rival traditions. As conventional economics shows itself unable to cope with the pace and complexity of change, we depend on people, and on our capacity to learn from our experiences and the experiences of others.

EJWI, published from the new University of Agder, offers a modern version of the Penny University, which was first seen in seventeenth century London coffee shops. Today a smart phone gives the user access to debate, dialogue, and a rich learning environment. This can bring innovation and participation to the Knowledge Workplace.

The European Journal of Workplace Innovation has the opportunity to develop a sustainable presence at the interstices of research, practice and education. As Europe experiences financial and economic fragility, governments implement austerity programmes, and the realisation grows that productivity needs to be improved, we can facilitate vital debate. We can respond to demand, and create new opportunities for particular groups, such as Masters students in a network of universities, who need to be able to think outside their local boxes. A Department of Working Life and Innovation can address a global audience. 